\title{
Concurso Internacional de Arquitectura Sustentable ASADES Taller Chauriye / Quinto y Sexto Semestre, FAU, Universidad de Chile
}

Durante el segundo semestre del año 2008, el taller de Diseño Arquitectónico de tercer año de la Facultad de Arquitectura y Urbanismo de la Universidad de Chile, dirigido por los académicos Rodrigo Chauriye, Christian Yutronic y Osvaldo Moreno, participó en el Concurso Internacional de Arquitectura Sustentable, ASADES, realizado en Mendoza, Argentina. Las propuestas de los alumnos Domingo Arancibia + Carlos Moreno y Sebastián Cruz + Cristián Merino, fueron premiadas con la Primera y Segunda Mención Honrosa, respectivamente.

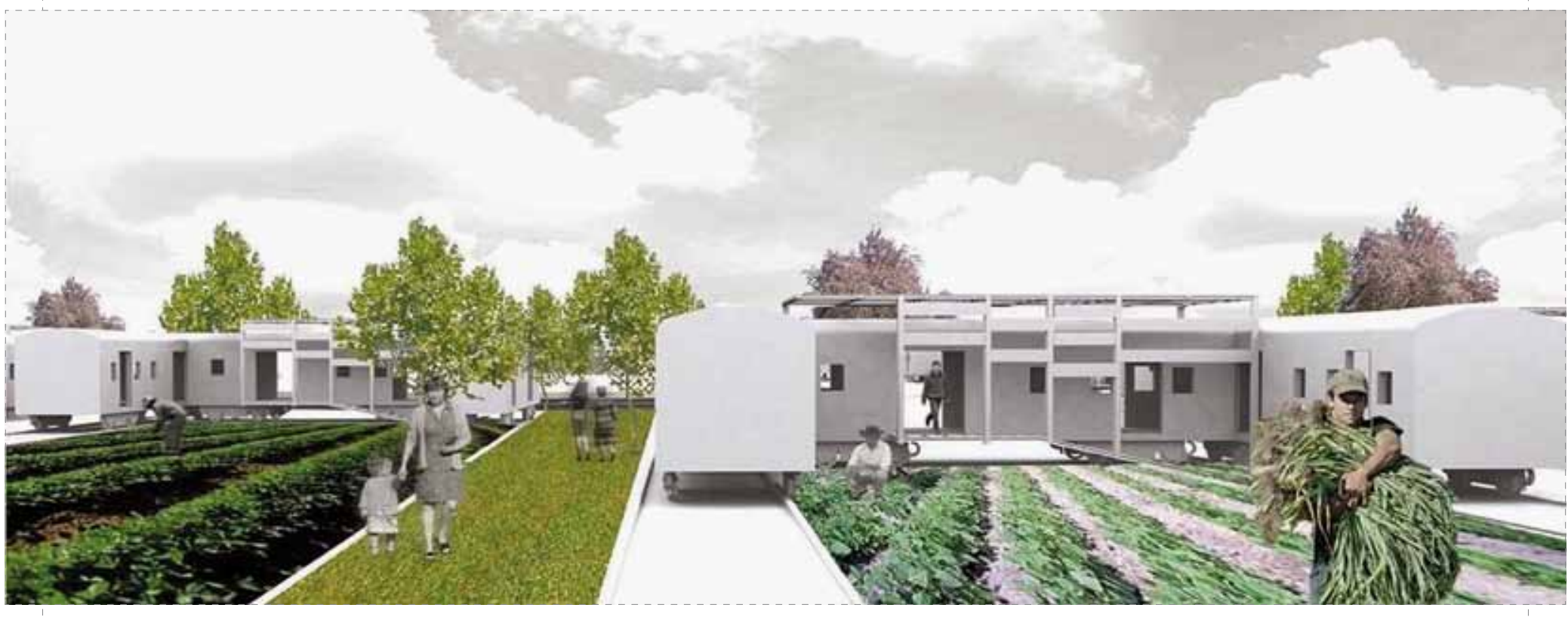

CONJUNTO VIVIENDA.

MAESTRANZA SAN EUGENIO

Domingo Arancibia + Carlos Moreno

\section{Ubicación}

Ubicación del proyecto: Santiago de Chile, Región Metropolitana comuna de Estación Central. Terreno colindante con la ex Maestranza ferroviaria San Eugenio en desuso desde 1985. La Región Metropolitana representa un clima templado cálido con lluvias invernales, pudiéndose distinguir dos subtipos que se diferencian entre sí por la duración de la estación seca. Clima templado cálido con lluvias invernales y una estación seca prolongada de 7 a 8 meses. Clima templado cálido con estación seca de 4 a 5 meses.

Breve historia Maestranza

Maestranza de San Eugenio, ubicada en la comuna de Estación Central, provincia de Santiago, Región Metropolitana, posee la significación de estar asociada a la evolución de la ciudad de Santiago habiéndola acompañado en un siglo, donde su crecimiento estuvo fuertemente condicionado, entre otros factores, por el desarrollo de transporte y de la infraestructura ferroviaria. La evolución de la ciudad y el desarrollo en las últimas décadas de nuevos medios de transporte ha traído consigo la decadencia de las estructuras de ferrocarriles, desapareciend una a una casi la totalidad de ellas, por lo que la Maestranza de San Eugenio se torna cas en el último testimonio en funcionamiento de la presencia, desarrollo y decadencia de la estructura ferroviaria en la ciudad de Santiago, siendo testigo de ese desarrollo, de los cambios tecnológicos y de la planificación urbana. En el año 1905 la empresa EFE adquirió $147.762 \mathrm{~m}^{2}$ de terreno, a unos $2 \mathrm{~km}$ al sureste de la Estación Alameda. El período de mayor desarrollo de la Maestranza de San Eugenio no partió sino hasta fines del decenio de 1920 y mediados de 1930. 

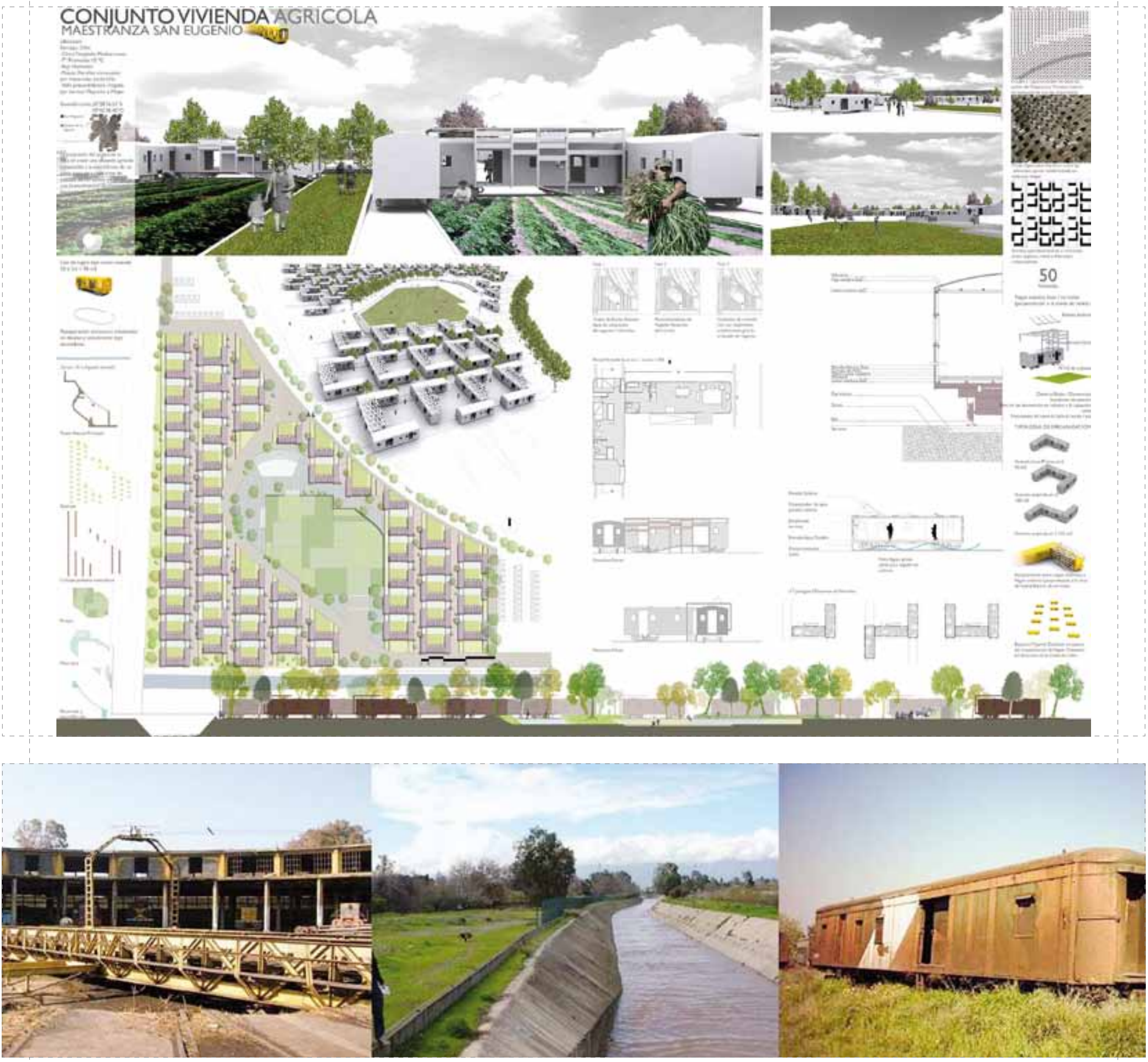

Reutilización de desechos

En el sector escogido de la ex Maestranza de San Eugenio, se encontraban un sinnúmero de desechos que nos hablan de la identidad del lugar y un pasado con actividad ferroviaria en el sector. Los desechos más característicos a la hora de hablar del carácter ferroviario encontrados en el lugar son: Vagones en desuso, rieles y durmientes. La propuesta del proyecto se basa en crear una vivienda agrícola sustentable a través de las bondades de un suelo apto para toda clase de cultivos horizontales, a través de la reutilización de elementos ferroviarios, manteniendo así la identidad del lugar 
PARQUE EDUCACIONAL

DEL RECICLAJE ORGÁNICO

Sebastian Cruz + Cristián Merino

\section{Empl azami ento}

Comuna de Santiago, extremo poniente Parque de los Reyes; latitud 33 23' 34" - longitud $70^{\circ} 40^{\prime}$ 37"; clima templado mediterráneo, $\mathrm{T}^{\circ}$ promedio: $14^{\circ} \mathrm{C}-15^{\circ} \mathrm{C}$, humedad relativa baja. Paisaje xerófito compuesto de matorral esclerófilo valle precordillerano irrigado por los Ríos Mapocho y Maipo. El sector se encuentra descuidado y olvidado por la Municipalidad.

\section{Ргоpuesta}

En la comuna de Santiago no existen programas dedicados al reciclaje orgánico (del cual se obtiene el compost, un efectivo abono), además de ser éste una práctica escasamente aplicada debido a su falta de difusión. La propuesta para el terreno busca revitalizar este extremo del parque; para esto se propone la implementación de un centro de reciclaje orgánico, enfocado a mostrar este proceso de manera educativa.

\section{Método de análisis y formalización}

Para el análisis del terreno se midió la intensidad de uso del suelo mediante la revisión audiovisual en distintos períodos de un día (mañana y tarde). El resultado es una cartografía, la cual se usa para definir los criterios del trazado. Además ésta se traspasó a un modelo en tres dimensiones que determina el criterio formal y espacial. Este criterio está basado en placas sucesivas que aparecen como muros o marcos estructurales en el proyecto. Para definir el programa se analizó el tema en base a dos premisas, la de educar y de reciclar. Éstas las entendemos como dos procesos lineales que interceptándose dan origen a la propuesta de un centro educacional para el reciclaje.

\section{Formal ización}

Para posicionarse en el terreno se tomaron los espacios desocupados que dejaba ver la cartografía, ya que ésta mostraba flujos e intensidades de uso permitido para tomar las decisiones del trazado. Al posicionarse además se toma la decisión de enterrarse, ya que el programa requiere espacios de dimensiones tales, que romperán el paisaje del parque. A enterrarse además se logra acondicionar los distintos sectores del programa de manera

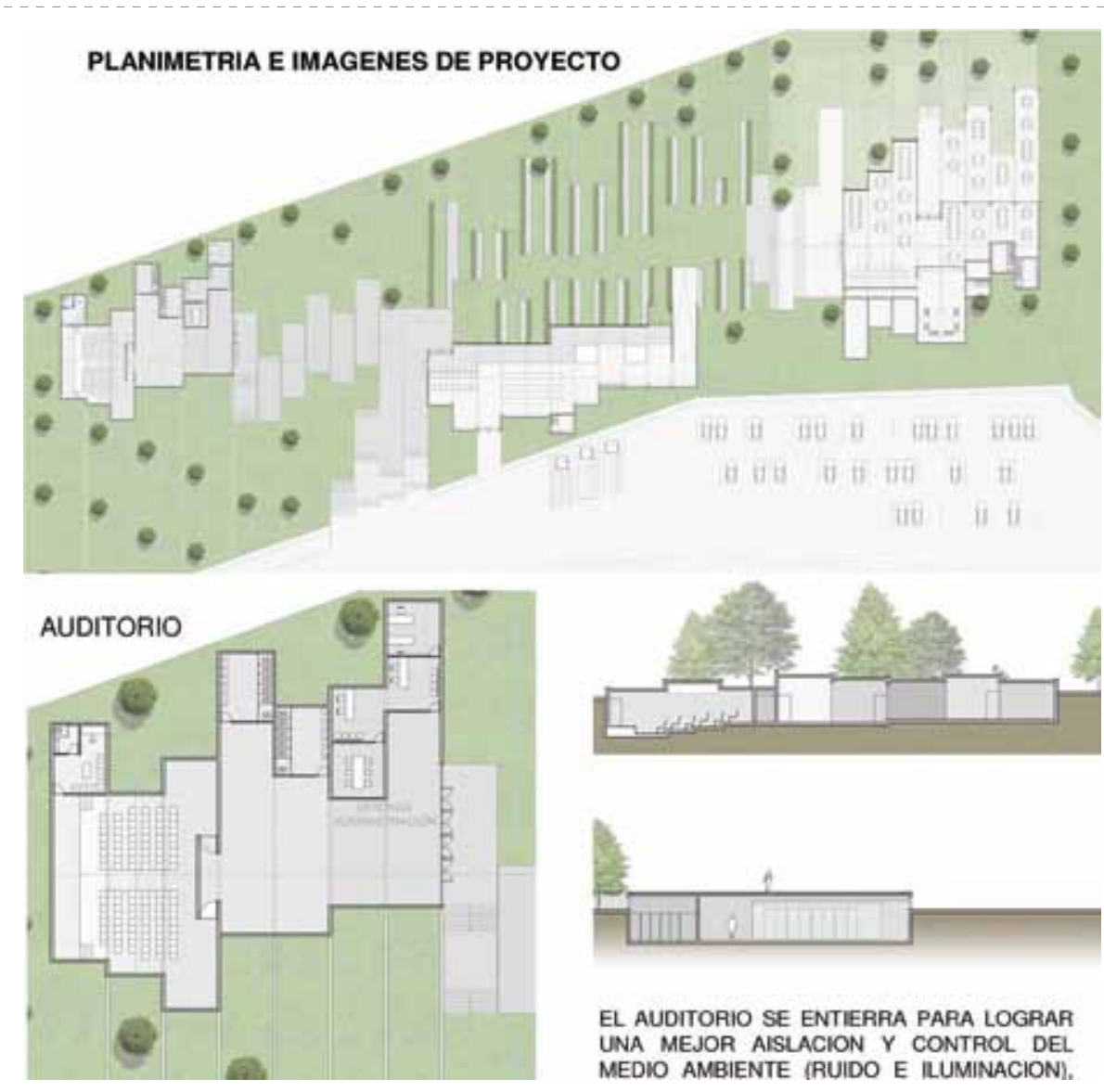

adecuada insistiendo que éste se encuentra en un parque. El sector intervenido es un sector abandonado y por ende sin recursos. Se plantean especies de fácil mantención y se propone la implementación de cubiertas verdes las cuales son un gran aporte en el ahorro energético.

\section{Cubiertas verdes}

Son capaces de retener hasta el $90 \%$ de la precipitación. Reducen el calentamiento atmosférico y humedecen el ambiente urbano creando así un clima más agradable. Reducen la reflexión sonora hasta $3 \mathrm{db}$ y son capaces de mejorar la insonorización hasta $8 \mathrm{db}$. Ofrecen protección frente a la radiación solar y aprovechan el efecto amortiguador de la temperatura que tiene la tierra gracias a su inercia térmica, de modo que se reducen tanto las pérdidas como las ganancias excesivas de energía o calor a través de la cubierta. Este efecto supone un aumento de las condiciones de confort y, a largo plazo, un ahorro energético por climatización.

\section{Auditorio}

El auditorio se entierra para lograr una mejor aislación y control del medio ambiente (ruido e iluminación), además de lograr una relación más amable con el entorno.

\section{Edificio reciclaje}

Se plantean dos espacios a distinta altura, unidos por el pasillo de circulación, ubicado para poder ver todo el proceso de reciclaje sin interrumpir a los trabajadores del lugar.

El restaurante orgánico se plantea como el final del recorrido, donde se utilizan los productos producidos por la huerta. El lugar de comedores se encuentra semienterrado para dar cierta privacidad a los usuarios.

\section{Restaurante}



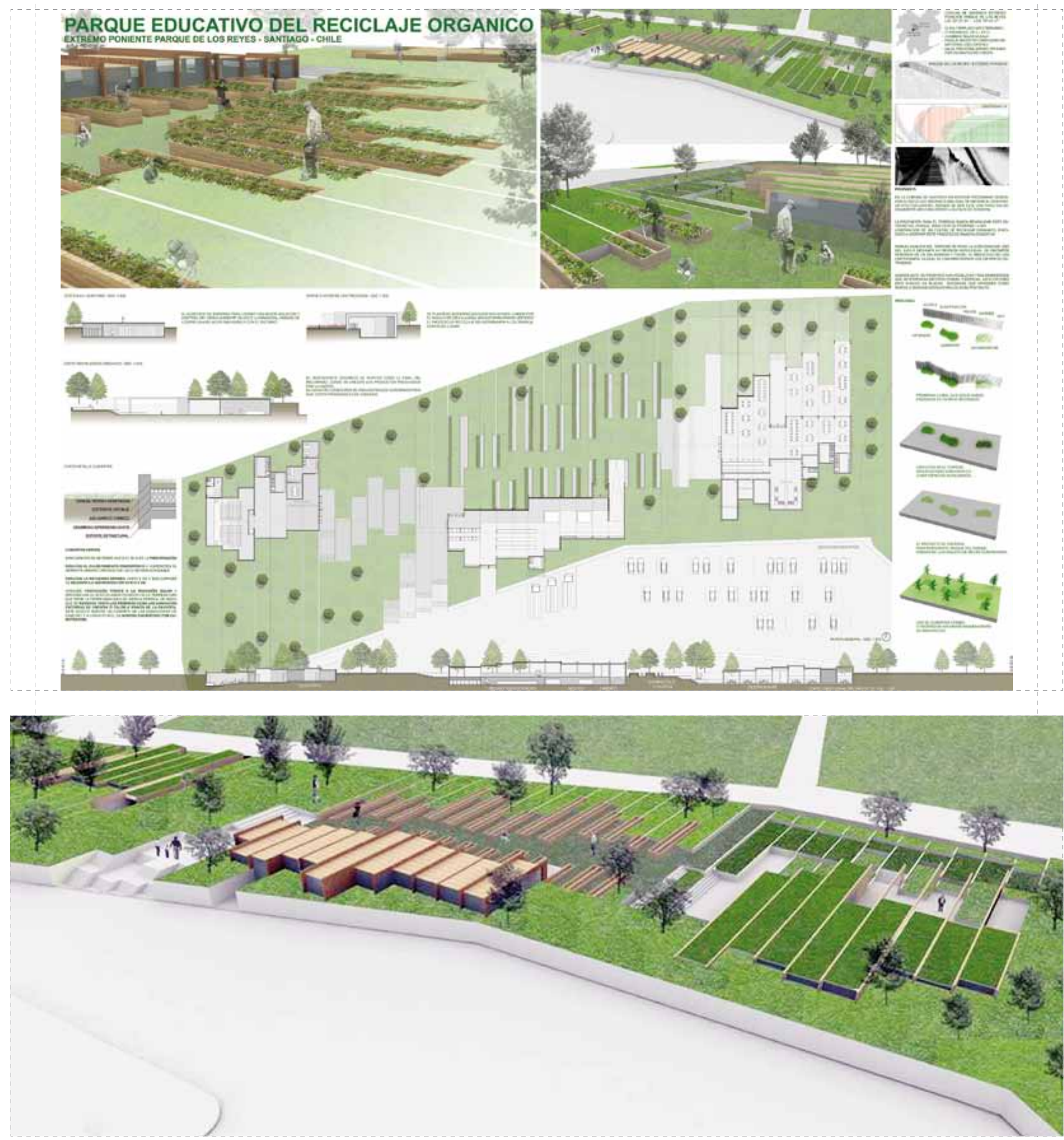